\title{
Comparison of High Performance Liquid Chromatography and Three Titrimetric Methods for the Determination of Ceftazidime in Pharmaceutical Formulations
}

\author{
Andréia de Haro Moreno, Hérida Regina Nunes Salgado*
}

\author{
Department of Drugs and Medicines, School of Pharmaceutical Sciences, University of São Paulo State, Araraquara, 14801-902, Brazil
}

\begin{abstract}
Three different assays for the quality control of ceftazidime in commercial formulations were developed and compared: acidimetric, iodometric and nonaqueous methods. Method validation yielding good results and included precision and accuracy, with good recovery percent ranged from 99.67 to 100.39 , and R.S.D. values smaller than $2 \%$. Results were compared to those obtained by high performance liquid chromatographic method, developed and published previously by us, and no evidence of significant difference was observed. The results obtained agreed well with the contents stated on the labels, being rapid, simple and inexpensive alternative method for the determination of ceftazidime in pharmaceutical formulations.
\end{abstract}

Keywords Ceftazidime, HPLC, Method Comparison, Pharmaceutical Analysis, Quality Control, Titrimetry

\section{Introduction}

Ceftazidime is a semisynthetic cephalosporin of the third generation with high antibacterial activity, widely used in the treatment of commonly-occurring bacterial infections, including indole-positive Proteus species and Pseudomonas aeruginosa and have been considered to be the drugs of choice for serious infections caused by Klebsiella, Enterobacter, Proteus, Providencia, Serratia and Haemophylus species[1-7]. They include biliary-tract infections, bone and joint infections, cystic fibrosis (respiratory-tract infections), endophthalmitis, infections in immunocompromised patients (neutropenic patients), meningitis, peritonitis, pneumonia, septicaemia, skin infections (including burns, ulceration) and urinary-tract infections[1,8-11]. Favorable properties of ceftazidime include efficient penetration of the bacterial cell wall, resistance to bacterial enzyme degradation, a high intrinsic activity against the bacterial cell targets, a broad spectrum of activity, very low toxicity, extensive tissue penetration, metabolic stability, and a low degree of serum protein binding[9,12-14]. The chemical structure of ceftazidime is represented by Figure 1. Ceftazidime is administrated by injection as the sodium salt or in solution

* Corresponding author:

salgadoh@fcfar.nesp.br (Hérida Regina Nunes Salgado)

Published online at http://journal.sapub.org/acc

Copyright (C) 2012 Scientific \& Academic Publishing. All Rights Reserved with arginine and is widely distributed in body tissues and fluids; it crosses the placenta and is distributed into breast milk[15]. Penetration into the aqueous humor of the eye is relatively good after systemic administration of ceftazidime[1,16,17]. There is some evidence that concentrations sufficient for therapy of ocular infections due to gram-positive and certain gram-negative microorganisms can be achieved after systemic administration[15].

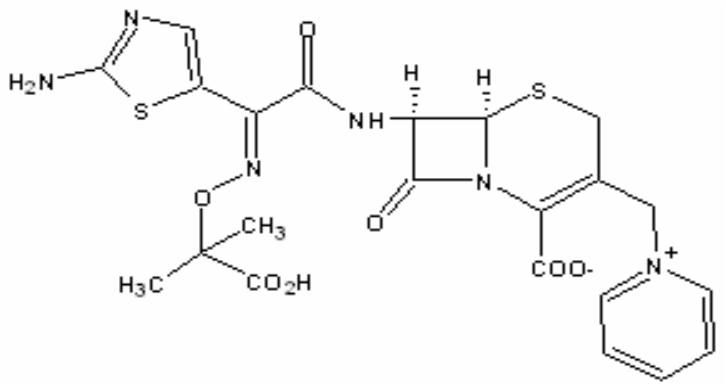

Figure 1. Chemical structure of ceftazidime $-\mathrm{C}_{22} \mathrm{H}_{22} \mathrm{~N}_{6} \mathrm{O}_{7} \mathrm{~S}_{2}$ (mw $546.58)$

For Several analytical procedures are available in the literature for the analysis of cephalosporins. These methods are spectrophotometry[18-27], high performance liquid chromatography[28-32], capillary electrophoresis[33], fluorimetry[34-38], polarography[39-43] and titrimetry[44].

Although ceftazidime has been studied in terms of therapeutic activity and commercialized, there is only one official pharmacopoeial monograph on its quantification by 
HPLC[45-47]. Recently, Moreno and Salgado published four methods for the analysis of ceftazidime in powder for injection: microbiological assay[48], high performance liquid chromatography[49] and spectrophotometry[50,51]. Therefore, the aim of this study was developed and validated a new and unpublished iodometric titration for quantitative determination of ceftazidime in powder for injection and comparing the results to those obtained by high performance liquid chromatography.

\section{Material and Methods}

\subsection{Chemicals}

Ceftazidime reference substance (assigned purity 99.98\%) and ceftazidime powder for injection were kindly supplied by Ariston Química e Farmacêutica Ltda. (São Paulo, Brazil). Ceftazidime powder for injection $\left(\right.$ Ceftazidon $^{\mathrm{TM}}$ ) was claimed to contain $1000 \mathrm{mg}$ (as anhydrous base) of the drug and $118 \mathrm{mg}$ of anhydrous sodium carbonate as excipient (solubilizer).

Solutions were made according to USP Pharmacopeia 2008 (45). All chemicals used were from analytical grade.

a) $0.1 \mathrm{M}$ hydrochloric acid: $8.5 \mathrm{~mL}$ of hydrochloric acid (Merck, Darmstadt, Germany) were diluted with water to $1000 \mathrm{~mL}$. This solution was standardized as following: $1.5 \mathrm{~g}$ of sodium carbonate (Merck, Darmstadt, Germany) previously crushed lightly and dried at $270^{\circ} \mathrm{C}$ for $1 \mathrm{~h}$ ) were accurately weighed and dissolved in $100 \mathrm{~mL}$ of water. So, 2 drops of methyl red solution were added and titrated with the hydrochloric solution to the production of a permanent pale pink color. Each $52.99 \mathrm{mg}$ of sodium carbonate is equivalent to $1 \mathrm{~mL}$ of $0.1 \mathrm{M}$ hydrochloric acid.

b) $1 \mathrm{M}$ hydrochloric acid: $85.0 \mathrm{~mL}$ of hydrochloric acid (Merck, Darmstadt, Germany) was diluted with water to $1000 \mathrm{~mL}$;

c) $0.01 \mathrm{M}$ iodine: $14.0 \mathrm{~g}$ of iodine was dissolved in an aqueous potassium iodide solution ( $36 \%$, w/v) and 3 drops of hydrochloric acid was added; so, this solution was diluted with water to $1000 \mathrm{~mL}$, and standardized as United States Pharmacopeia (45). An aliquot of $50 \mathrm{~mL}$ of this solution was diluted in water to make $1000 \mathrm{~mL}$;

d) 0.1 N perchloric acid: $8.5 \mathrm{~mL}$ of perchloric acid (Merck, Darmstadt, Germany) were mixed with $500 \mathrm{~mL}$ of glacial acetic acid (Merck, Darmstadt, Germany) and $21 \mathrm{~mL}$ of acetic anhydride (Merck, Darmstadt, Germany), cooled, and added glacial acetic acid to make $1000 \mathrm{~mL}$. This solution was standardized as follows: $700 \mathrm{mg}$ of potassium biphthalate were accurately weighed (previously dried at $120^{\circ} \mathrm{C}$ for 2 h) and dissolved in $50 \mathrm{~mL}$ of glacial acetic acid in a flask. So, 2 drops of crystal violet solution were added, and titrated with perchloric acid solution until blue-green color. Each $20.42 \mathrm{mg}$ of potassium biphthalate is equivalent to $1 \mathrm{~mL}$ of $0.1 \mathrm{~N}$ perchloric acid.

e) $0.1 \mathrm{M}$ sodium hydroxide: $4.0 \mathrm{~g}$ of sodium hydroxide (Merck, Darmstadt, Germany) was dissolved in $150 \mathrm{~mL}$ of carbon dioxide-free water, cooled at room temperature and diluted with carbon dioxide-free water to $1000 \mathrm{~mL}$. This solution was standardized as following: $5 \mathrm{~g}$ of potassium biphthalate (previously dried at $120^{\circ} \mathrm{C}$ for $2 \mathrm{~h}$ ) were accurately weighed and dissolved in $75 \mathrm{~mL}$ of carbon dioxide-free water in a flask. After, 2 drops of phenolphthalein solution were added, and titrated with the sodium hydroxide solution to the production of a permanent pink color. Each $20.42 \mathrm{mg}$ of potassium biphthalate is equivalent to $1 \mathrm{~mL}$ of $0.1 \mathrm{M}$ sodium hydroxide.

f) $1 \mathrm{M}$ sodium hydroxide: $40.0 \mathrm{~g}$ of sodium hydroxide (Merck, Darmstadt, Germany) was dissolved in water to make $1000 \mathrm{~mL}$;

g) $0.01 \mathrm{M}$ sodium thiosulphate: $26 \mathrm{~g}$ of sodium thiosulphate (Merck, Darmstadt, Germany) was dissolved in water to make $1000 \mathrm{~mL}$. An aliquot of $50 \mathrm{~mL}$ of this solution was diluted in water to make $1000 \mathrm{~mL}$;

h) Acetate buffer solution: $5.44 \mathrm{~g}$ of sodium acetate (Merck, Darmstadt, Germany) and $2.40 \mathrm{~g}$ of glacial acetic acid were dissolved in water to make $100 \mathrm{~mL}$.

i) Crystal violet 1\%(w/w): $100 \mathrm{mg}$ of crystal violet (Merck, Darmstadt, Germany) were dissolved to $10 \mathrm{~mL}$ of glacial acetic acid.

j) Methyl red 0.1\% (w/w): $100 \mathrm{mg}$ of methyl red (Merck, Darmstadt, Germany) were dissolved in $100 \mathrm{~mL}$ of alcohol and filtered.

k) Phenolphthalein 1\%(w/w): $100 \mathrm{mg}$ of phenolphthalein (Merck, Darmstadt, Germany) were dissolved in $100 \mathrm{~mL}$ of alcohol and filtered.

1) Starch mucilage: $1 \mathrm{~g}$ of soluble starch was mixed with $10 \mathrm{mg}$ of red mercuric iodide and sufficient cold water to make a thin paste. So, $200 \mathrm{~mL}$ of boiling water was added with continuous stirring. After cool, the clear solution was used.

\subsection{Procedure}

In order to determine the average weight, contents of 20 flasks of ceftazidime powder for injection (vials) were individually weighed and mixed.

a) Acidimetric method: an accurately weighed portion of the power equivalent to $500 \mathrm{mg}$ of the drug was transferred in a $250 \mathrm{~mL}$ conical flask and dissolved with $25 \mathrm{~mL}$ of carbon dioxide-free water (previously neutralized with $0.1 \mathrm{M}$ hydrochloric acid). An aliquot of $25.0 \mathrm{~mL}$ of $0.1 \mathrm{M}$ sodium hydroxide was added and heated in a water bath at $80^{\circ} \mathrm{C}$ for 20 minutes. This time was found appropriate for complete hydrolysis of cephalosporins[22]. The solution was cooled at room temperature, and 2 drops of phenolphthalein solution were added and the excess of sodium carbonate was titrated with $0.1 \mathrm{M}$ hydrochloric acid. A blank determination was performed and the difference between titrations represented the volume of $0.1 \mathrm{M}$ sodium hydroxide equivalent to quantity of ceftazidime present. This procedure was performed in triplicate. Each $\mathrm{mL}$ of $0.1 \mathrm{M}$ sodium hydroxide is equivalent to $54.658 \mathrm{mg}$ of ceftazidime (as anhydrous base).

b) Non aqueous method: An accurately weighed portion of 
powder equivalent to $250 \mathrm{mg}$ of drug was dissolved in water and transferred to a $250 \mathrm{~mL}$ conical flask, dissolved with 30 $\mathrm{mL}$ of glacial acetic acid and 2 drops of crystal violet solution were added and mixed. Drug was titrated with $0.1 \mathrm{~N}$ perchloric acid until the blue-green color. A blank determination was performed at $20^{\circ} \mathrm{C}$ and any necessary corrections were made. This procedure was performed in triplicate. Each $\mathrm{mL}$ of $0.1 \mathrm{~N}$ perchloric acid is equivalent to $54.658 \mathrm{mg}$ of ceftazidime (as anhydrous base).

c) Iodometric method: An accurately weighted portion of the power equivalent to $100 \mathrm{mg}$ of the drug was dissolved in water and transferred in a $100 \mathrm{~mL}$ volumetric flask $(1000$ $\mu \mathrm{g} / \mathrm{mL}$ ). An aliquot of $10 \mathrm{~mL}$ was transferred to a stopped flask, added $5 \mathrm{~mL}$ of $1 \mathrm{M}$ sodium hydroxide, and allowed to stand for twenty minutes. So, $20 \mathrm{~mL}$ of a freshly prepared acetate buffer solution, $5 \mathrm{~mL}$ of $1 \mathrm{M}$ hydrochloric acid, and $25 \mathrm{~mL}$ of $0.01 \mathrm{M}$ iodine were added and the flask closed with a wet stopper. After 20 minutes, protected from light, the excess of iodine was titrated with $0.01 \mathrm{M}$ sodium thiosulphate, using starch mucilage, added towards the end of the titration, as indicator. To a further $10 \mathrm{~mL}$ of the ceftazidime solution $(1000 \mu \mathrm{g} / \mathrm{mL})$ was added $20 \mathrm{~mL}$ of the acetate buffer solution and $25 \mathrm{~mL}$ of $0.01 \mathrm{M}$ iodine, allowed to stand for twenty minutes and titrated with $0.01 \mathrm{M}$ sodium thiosulphate, using starch mucilage, added towards the end of the titration, as indicator. A blank determination was performed at a temperature of $20^{\circ} \mathrm{C}$ and any necessary corrections were made. The difference between titrations represents the volume of $0.01 \mathrm{M}$ iodine equivalent to the ceftazidime present. Each $\mathrm{mL}$ of $0.01 \mathrm{M}$ iodine is equivalent to $1.5915 \mathrm{mg}$ of ceftazidime (as anhydrous base).

\subsection{Method validation}

The three titrimetric methods were validated by the following parameters: precision and accuracy. The recovery percentage of ceftazidime added was calculated using the equation proposed by AOAC[52].

a) Precision: Repeatability (intraday) and intermediate precision (interday) of the proposed assay were evaluated. Repeatability was studied by the assay of independent samples, during the same day under the same experimental conditions. Intermediate precision was evaluated by comparing the results obtained on 3 different days. Precision was expressed as percent coefficient of variation. Analysis of variance (ANOVA) is an important statistical tool to verify the internal validity of an analytical procedure.

b) Accuracy: This parameter was determined by the recovery study, comparing the theoretical and measured concentrations of known amounts of ceftazidime reference substance added at the beginning of the process. For the acidimetric method, the equivalent to $5000 \mathrm{mg}$ of ceftazidime reference substance was dissolved in sufficient water to produce $500 \mathrm{~mL}(10.0 \mathrm{mg} / \mathrm{mL})$. Amounts of ceftazidime powder for injection (equivalent to $500 \mathrm{mg}$ of the drug) were transferred to $250 \mathrm{~mL}$ conical flasks $\left(\mathrm{R}_{1}, \mathrm{R}_{2}\right.$ and $\left.\mathrm{R}_{3}\right)$ and dissolved with $25 \mathrm{~mL}$ of carbon dioxide-free water (neutralized with $0.1 \mathrm{M}$ hydrochloric acid). Portions of 2.5, 5.0 and $10.0 \mathrm{~mL}$ of ceftazidime reference substance $(10.0$ $\mathrm{mg} / \mathrm{mL}$ ) were added to flasks $\mathrm{R}_{1}, \mathrm{R}_{2}$ and $\mathrm{R}_{3}$, respectively. Aliquots of $25.0 \mathrm{~mL}$ of $0.1 \mathrm{M}$ sodium hydroxide were added and heated in a water bath at $80^{\circ} \mathrm{C}$ for 20 minutes. After the solutions were cooled at room temperature, 2 drops of phenolphthalein solution were added in each flask and the excess of sodium hydroxide was titrated with $0.1 \mathrm{M}$ hydrochloric acid. A blank determination was performed and the difference between the titrations represented the volume of $0.1 \mathrm{M}$ sodium hydroxide equivalent to ceftazidime present. This procedure was performed in triplicate. Each $\mathrm{mL}$ of 0.1 $\mathrm{M}$ sodium hydroxide is equivalent to $54.658 \mathrm{mg}$ of ceftazidime (as anhydrous base).

For nonaqueous method, the equivalent to $2500 \mathrm{mg}$ of ceftazidime reference substance was dissolved in sufficient glacial acetic acid to produce $500 \mathrm{~mL}(5.0 \mathrm{mg} / \mathrm{mL})$. Amounts of ceftazidime powder for injection (equivalent to $250 \mathrm{mg}$ of the drug) were transferred to $250 \mathrm{~mL}$ conical flasks $\left(\mathrm{R}_{1}, \mathrm{R}_{2}\right.$ and $\mathrm{R}_{3}$ ) and dissolved with $30 \mathrm{~mL}$ of glacial acetic acid. Portions of 2.5, 5.0 and $10.0 \mathrm{~mL}$ of ceftazidime reference substance $(5.0 \mathrm{mg} / \mathrm{mL})$ were added to flasks $R_{1}, R_{2}$ and $R_{3}$, respectively. After, 2 drops of crystal violet solution were added in each flask and the solutions were titrated with $0.1 \mathrm{~N}$ perchloric acid until the blue-green color. A blank determination was performed at $20^{\circ} \mathrm{C}$ and any necessary corrections were made. This procedure was performed in triplicate. Each $\mathrm{mL}$ of $0.1 \mathrm{~N}$ perchloric acid is equivalent to $54.658 \mathrm{mg}$ of ceftazidime (as anhydrous base).

For iodometric method, recoveries were determined by adding known amounts of ceftazidime reference substance $(0.5,1.0$ and $2.0 \mathrm{mg})$ to the samples at the beginning of the procedure. Ceftazidime reference substance and powder for injection were dried in vacuum at a pressure not exceeding 5 $\mathrm{mm}$ of mercury at $60^{\circ} \mathrm{C}$ for 3 hours. The equivalent of 125 $\mathrm{mg}$ ceftazidime reference substance was dissolved in sufficient water to produce $25 \mathrm{~mL}(5 \mathrm{mg} / \mathrm{mL})$. Amounts of 1.0 , 2.0 and $4.0 \mathrm{~mL}$ of this solution were added with the sample (aliquot of $10 \mathrm{~mL}$ ) and transferred to a stopped flask, added 5 $\mathrm{mL}$ of $1 \mathrm{M}$ sodium hydroxide, and allowed to stand for 20 minutes. After, $20 \mathrm{~mL}$ of a freshly prepared acetate buffer solution, $5 \mathrm{~mL}$ of $1 \mathrm{M}$ hydrochloric acid, and $25 \mathrm{~mL}$ of 0.01 $\mathrm{M}$ iodine were added and the flask closed with a wet stopper, and allowed to stand for 20 minutes, protected from light. Excess of iodine was titrated with $0.02 \mathrm{M}$ sodium thiosulphate, using starch mucilage, added towards the end of the titration, as indicator. To a further $10 \mathrm{~mL}$ of ceftazidime solution $(1000 \mu \mathrm{g} / \mathrm{mL})$ was added $20 \mathrm{~mL}$ of acetate buffer solution and $25 \mathrm{~mL}$ of $0.01 \mathrm{M}$ iodine, allowed to stand for twenty minutes and titrated with $0.02 \mathrm{M}$ sodium thiosulphate, using starch mucilage, added towards the end of the titration, as indicator. The difference between titrations represents the volume of $0.01 \mathrm{M}$ iodine equivalent to the ceftazidime present.

c) Method comparison: Results obtained in this study were compared to those obtained by a high performance liquid chromatography method, previously developed and validated by us[49]. 


\section{Results and Discussion}

\section{Acidimetric method}

Cephalosporins are antibiotics widely used to the treatment of various bacterial infections. The minimum requirement for the activity of this drug group is the presence of the beta-lactam ring connected to the acid group (Figure 1). Most chemical methods of assay for the cephalosporins depend upon hydrolytic cleavage of the $\beta$-lactam ring to give cephalosporanic acid.

Antibiotic hydrolytic degradation is frequently used as preliminary stage in the quantification analytical procedures, being the alkaline hydrolysis the most common[24,53]. According to Korolkovas[53], penicillins and cephalosporins can be determined by alkaline hydrolysis of beta-lactam ring using known accurately amount of sodium hydroxide solution, providing the sodium salt of penicilloic acid derived. After, excess of sodium hydroxide solution is quantified by standardized acid solution (generally hydrochloric acid).

Ceftazidime commercial sample used in this study (powder for injection) presented in its composition sodium carbonate as excipient (solubilizer), equivalent to $2.3 \mathrm{mEq} \mathrm{Na}+$ in $10 \mathrm{~mL}$ of reconstituted sample. This excipient interferes with the assay (also reacts with the acid solution used to quantify sodium hydroxide excess). So, this interference was eliminated by sample neutralization with hydrochloric acid solution at room temperature before alkaline hydrolysis (that occurs generally by heat). This procedure not provided interference in the calculations, according to the results obtained and values subsequently presented by the recovery study.

Experimental values obtained for ceftazidime powder for injection are presented in Table 1, showing the agreement between the accepted value and the value found to be $100.13 \%$ for powder for injection.

Precision and accuracy of the assay were also demonstrated. Precision is usually expressed as the variance, relative standard deviation (R.S.D.), or coefficient of variation (C.V.\%) of a series of measurements[54]. Results obtained through the acidimetric assay in 3 different days showed a R.S.D. less than $2 \%(0.633 \%)$, indicating good repeatability of the assay (Table 1).

Accuracy was measured by the recovery test, which was obtained by comparing the experimental values to the calculated theoretical concentrations. The mean absolute recovery test of acidimetric assay was found to be $100.39 \pm$ $0.83 \%$, indicating a good accuracy and the agreement with the spiked amount of reference substance (Table 2).

Pharmacopeias don't recommend acidimetric assay for cephalosporins; so, the proposed assay showed simple, accessible and unpublished for the quantification of ceftazidime. Data obtained by the proposed assay were statistically compared by ANOVA test with the one obtained by HPLC method previously developed and validated by us (Table 3). It was indicated that there is no evidence of significant difference between these methods $(p<0.05)$. For this reason, the proposed assay showed appropriate for the determination of ceftazidime in powder for injection and can be used in routine quality control analysis.

Table 1. Experimental values obtained for the determination of ceftazidime by acidimetric, iodometric and nonaqueous proposed methods.

\begin{tabular}{lcccc}
\hline \multirow{2}{*}{ Sample } & \multicolumn{3}{c}{ Ceftazidime content (\%) \pm S.D. } \\
\cline { 2 - 5 } & Acidimetry & Iodometry & Nonaqueous & HPLC * \\
\hline Day 1 & $101.50=0.226$ & $99.39=0.704$ & $99.62=0.333$ & $99.14=0.175$ \\
Day 2 & $99.90=0.898$ & $99.25=0.557$ & $99.16=0.737$ & $99.29=0.926$ \\
Day 3 & $98.99=0.778$ & $100.59=0.617$ & $99.50=0.728$ & $99.27=.0742$ \\
& & & & \\
Mean (inter-asay) & $100.13=0.634$ & $99.74=0.626$ & $99.43=0.599$ & $99.23=0.614$ \\
RSD, \% & 0.633 & 0.627 & 0.603 & 0.620 \\
\hline
\end{tabular}

S.D. $=$ Standar Deviation

R.S.D. = Relative Stand ard Deviation

Each value is the mean of six determinations

${ }^{*}$ Moreno and Salgado, 2008

Table 2. Experimental values obtained in the recovery test for ceftazidime by acidimetric, iodometric and nonaqueous proposed methods.

\begin{tabular}{cccc}
\hline Method & Added, $\mathrm{mg}$ & Found, $\mathrm{mg}$ & Recovery, \% \\
\hline \multirow{2}{*}{ Acidimetry } & 25.0 & 25.14 & 100.56 \\
& 50.0 & 24.87 & 99.48 \\
& 100.0 & 25.28 & 101.12 \\
Iodometry & 0.5 & 0.49 & 98.40 \\
& 1.0 & 1.01 & 101.10 \\
& 2.0 & 1.99 & 99.75 \\
Nonaqueous & 12.5 & 12.51 & 100.06 \\
& 25.0 & 25.14 & 100.56 \\
& 50.0 & 49.19 & 98.38 \\
\hline
\end{tabular}

Each value is the mean of six determinations

Table 3. Analysis of ceftazidime powder for injection by 2 different methods.

\begin{tabular}{lcccc}
\hline \multicolumn{1}{c}{ Methods } & Mean, $\%$ & R.S.D. $\%$ & $n$ & $p$-Value \\
\hline Acidimetry & 100.13 & 1.21 & 6 & \\
Iodometry & 99.74 & 0.63 & 6 & 0.5132 \\
Nonaqueous & 99.43 & 0.60 & 6 & \\
HPLC & 99.23 & 0.62 & 6 &
\end{tabular}

${ }^{*}$ Moreno and Salgado, 2008

\section{Nonaqueous method}

Nonaqueous titration is the most common titrimetric procedure used in pharmaceutical assays and serves a double purpose: it is suitable for the titration of very weak acids and very weak bases, and it provides a solvent in which organic compounds are soluble. The most commonly used procedure is the titration of organic bases with perchloric acid in anhydrous acetic acid. These assays sometimes take some perfecting in terms of being able to judge the endpoint precisely. Substances potentially acidic can function as acids only in the presence of a base to which they can donate a 
proton. Conversely basic properties do not become apparent unless an acid also is present $[18,19]$.

Determination of ceftazidime by nonaqueous assay showed simple, rapid, inexpensive, easy execution and did not require high cost equipments, reagents or long stage extraction procedures or sample preparations.

Nonaqueous assay did not require alkaline hydrolysis of beta-lactam ring when compared to aqueous assays. However, excipients (solubilizer) commonly present in ceftazidime commercial samples (anhydrous sodium carbonate or arginine) also react with the titrant (perchloric acid). So, for eliminate this interference and not realize extractive procedures, total volume of $0.1 \mathrm{~N}$ perchloric acid consumed was subtracted from volume consumed by sodium carbonate (excipient). This calculation as possible due to average weight determined to 20 flasks of ceftazidime powder for injection, found to be $1271.92 \pm 11.77 \mathrm{mg}$. Quantity of sodium carbonate present in each vial is $118 \mathrm{mg}$; so that, for $250 \mathrm{mg}$ of ceftazidime, powder contains $29.50 \mathrm{mg}$ of sodium carbonate that consume $5.57 \mathrm{~mL}$ of $0.1 \mathrm{~N}$ perchloric acid. For this reason, the volume reacted must be subtracted from total titrant volume consumed. This stage corrected the interference of excipient present in the sample analyzed (sodium carbonate) and also must be considered for arginine, with the necessary corrections, according to results obtained.

The results obtained through the nonaqueous assay using perchloric acid in 3 different days showed $99.43 \%$ of ceftazidime and relative standard deviation less than 1\% (R.S.D. $=0.60$ ), indicating good repeatability of the assay (Table 1).

Accuracy was measured by the recovery test, which was obtained by comparing experimental values to calculated theoretical concentrations. Mean absolute recovery test of nonaqueous assay was found to be $99.67 \pm 1.14 \%$, indicating a good accuracy and the agreement with the spiked amount of reference substance (Table 2).

Pharmacopeias don't also recommend nonaqueous assay for cephalosporins; so, the proposed assay showed simple, accessible and unpublished for the quantification of ceftazidime. Detection of end point can be accomplished potentiometrically or by visual detection.

Data obtained by this proposed assay were statistically compared by ANOVA test with the one obtained by HPLC method previously developed and validated by us (Table 3 ). It was indicated that there is no evidence of significant difference between the 2 methods $(p<0.05)$. For this reason, the proposed assay showed appropriate for the determination of ceftazidime in powder for injection and can be used in routine quality control analysis.

\section{Iodometric method}

Cephalosporins are antibiotics widely used to the treatment of various bacterial infections. The minimum requirement for the activity of this drug group is the presence of the beta-lactam ring connected to the acid group (Figure $1)$.

Most chemical methods of assay for cephalosporins depend upon hydrolytic cleavage of the beta-lactam ring to give cephalosporanic acid. This cleavage can be brought about either by alkali or by enzyme penicillinase. If cleavage is brought about by penicillinase in a previously neutral and not buffered solution the resulting acid may be titrated with alkali to give a measure of the drug present. Alternatively, and more commonly, liberated cephalosporanic acid is determined through its ability to take up iodine, a property not possessed by the parent molecule. It might be expected that one molecule of cephalosporin, after hydrolysis, would absorb eight atoms of iodine, but by experiment it is found that a variable amount is absorbed, depending on the exact conditions and this makes it necessary for a standard preparation and for standard conditions to be used.

The developed method has two principal advantages, first, it has a high degree of specificity since non-penicillin impurities are to a large extent allowed for in the blank determination and secondly, the relatively large iodine absorption makes the method highly sensitive. It will be noted, however, that in the procedure given above the blank determination is not a true control for the not hydrolyzed penicillin solution must be titrated immediately after addition of standard iodine; thus any slowly-absorbing impurities which may be present are not given time to react as they are in the determination itself where they are in contact with an excess of iodine for fifteen minutes at $30^{\circ} \mathrm{C}$. This treatment of the blank must be adopted because it was shown that iodine is slowly absorbed during the waiting period, probably because of break-down of penicillin. It is reported that this breakdown can be avoided by buffering the solution, and the fact the British Pharmacopoeia[46] uses acetate buffer of $\mathrm{pH} 4-5$, and under this conditions the blank solution may be treated in exactly the same way as the test solution, except that the hydrolysis period with sodium hydroxide is omitted.

Iodine is a moderately strong oxidizing agent used to oxidize substances with lower reduction potentials, as the titration of ascorbic acid, sodium stilbigluconate, dimercaprol injection and acetarsol. Iodine solution used in standardized against sodium thiosulphate. In addition, the end-point is detected using starch indicator, which produces a blue coloration with excess iodine.

A major stability problem in penicillins and cephalosporins is the hydrolysis of the lactam ring. These drugs with an open lactam ring are inactive as antibiotics since it is the reactive lactam ring which kills the bacteria. When the lactam ring is open it will react with iodine. 1 mole of the ring open form of penicillins and cephalosporins will react with 8 equivalents of iodine, the intact lactam ring will not react. In this type of titration excess iodine solution is added to a sample of the drug and the iodine not consumed in the reaction was estimated by titration with sodium thiosulphate. The value obtained for the amount of hydrolyzed drug in the sample should be no more than $5 \%$ of that obtained when all drug in the same amount of sample is completely hydrolyzed to the ring-opened form and then reacted with iodine. Most of pharmacopeial monographs for penicillins and cephalosporins indicate that this test should be carried out[1 $8-20,48]$.

Results obtained through the iodometric analysis with 
ceftazidime powder for injection are displayed in Table 1 , and the results of recovery test are shown in Table 2.

Standard deviation and coefficient of variation were found to be less than $1 \%$, indicating good repeatability of the iodometric titration. Relative standard deviation observed was approximately $0.63 \%$ and results obtained for ceftazidime powder for injection shown $99.74 \%$, indicating good repeatability of the assay.

Accuracy may be expressed as percent recovery by the assay of known, added amounts of drug[18]. The mean absolute recovery test of iodometric titration was $99.75 \%$, indicating a good accuracy and the agreement with spiked amount of reference substance.

No interference from sample solvent, impurities or powder excipients could be analysed by iodometric titration using blank sample or excipients. There was no evidence of interference from excipients in the powder for injection analysed.

This volumetric method proposed is simple, rapid and inexpensive and can therefore be applied to the determination of ceftazidime raw material and powder for injection. Method validation yielded good results and included precision and accuracy.

Results obtained in this study were compared by ANOVA with those obtained by a high-performance liquid chromatography (HPLC) method described previously[49]. It was indicated that there is no evidence of significant difference between these methods $(p<0.05)$, according to Table 3 .

Besides Pharmacopoeias recommend iodometric assay for cephalosporins[46], the proposed method is simple, accessible and unpublished for the quantification of this cephalosporin.

\section{Conclusions}

We could conclude that the acidimetric, nonaqueous and iodometric assays proposed are simple, rapid and inexpensive and can therefore be applied to the determination of ceftazidime in raw material and pharmaceuticals. Method validation yielding showed good results and included precision and accuracy. It was found that the excipient interference was eliminated, according to the results obtained. Results of statistic analysis showed this assay gives similar results to those obtained by HPLC, indicating that it allows reliable determination of ceftazidime and can be used for the quality control analysis.

\section{ACKNOWLEDGEMENTS}

Authors thank Ariston Química e Farmacêutica Ltda. (São Paulo, Brasil) for providing ceftazidime reference substance and ceftazidime powder for injection. This work was supported by PACD-FCFAr-UNESP-Brazil, FUNDUNESPBrazil, FAPESP-Brazil and CNPq-Brazil.

\section{REFERENCES}

[1] J.G. Hardman and L.E. Limbird, The Pharmacological Basis of Therapeutics, New York, NY: McGraw-Hill Book Co., 2006.

[2] Baskaran, N.D., Gan, G.G., Adeeba, K., Sam, I.C., 2007, Bacteremia in patients with febrile neutropenia after chemotherapy at a university medical center in Malaysia, Int. J. Infect. Dis., 23, 115-121.

[3] Cavallo, J.D., Hocquet, D., Plesiat, P., Fabre, R., Roussel-Delvallez, M., 2007, Susceptibility of Pseudomonas aeruginosa to antimicrobials: a 2004 French multicentre hospital study, J. Antimicrob. Agents Chemother., 59, 1021-1024.

[4] Claridge, J.A., Edwards, N.M., Swanson, J., Fabian, T.C., Weinberg, J.A., Wood, C., Croce, M.A., 2007, Aerosolized ceftazidime prophylaxis against ventilator-associated pneumonia in high-risk trauma patients: results of a double-blind randomized study, Surg. Infect. (Larchmt), 8, 83-90.

[5] Eagye, K.J., Kuti, J.L., Nicolau, D.P., 2007, Evaluating empiric treatment options for secondary peritonitis using pharmacodynamic profiling, Surg. Infect. (Larchmt), 8, 215-226.

[6] Martin, M.G., 2007, Encephalopathy with myoclonic jerks resulting from ceftazidime therapy: an under-recognized potential side-effect when treating febrile neutropenia, Leuk. Lymphoma, 48, 413-414.

[7] Raja, N.S., 2007, Antimicrobial susceptibility pattern of clinical isolates of Pseudomonas aeruginosa in a tertiary care hospital, J. Microbiol. Immunol. Infect., 40, 178-82.

[8] Rodenas, V., Garcia, M.S., Sanchez-Pedreno, C., Albero, M.I., 1997, Spectrophotometric methods for the determination of cephradine or ceftazidime in human urine using batch and flow-injection procedures, J. Pharm. Biomed. Anal., 15, $1687-1693$.

[9] Adamis, G., Papaioannou, M.G., Giamarellos-Bourboulis, E.J., Gargalianos, P., Kosmidis, J., Giamarellou, H., 2004, Pharmacokinetic interactions of ceftazidime, imiprenem and aztreonam with amikacin in healthy volunteers, Int. J. Antimicrob. Agents, 23, 144-149.

[10] A.R. Gennaro, Remington: The Science And Practice of Pharmacy, $20^{\text {th }}$ ed., Rio de Janeiro, Brazil: Guanabara Koogan, 2004.

[11] Martindale, The Complete Drug Reference, London, England: Pharmaceutical Press, 2005.

[12] Myers, C.M., and Blumer, J.L., 1983, Determination of ceftazidime in biological fluids by using high-pressure liquid chromatography, Antimicrob. Agents Chemother., 24, 343-346.

[13] Arséne, M., Favetta, P., Favier, B., Bureau, J., 2002, Comparison of ceftazidime degradation in glass bottles and plastic bags under various conditions, J. Clin. Pharm.Therap., 27, 205-209.

[14] Jamieson, C.E., Lambert, P.A., Simpson, I.N., 2003, In vitro activities of novel oxapenems, alone and in combination with ceftazidime, against Gram-positive and Gram-negative organisms. Antimicrobial Agents Chemotherapy, 47, 2615-2618. 
[15] Isla, A., Gascon, A.R., Maynar, J., Arzuaga, A., Sanchez-Izquierdo, J.A., Pedraz, J.L., 2001, In vitro AN69 and polysulphone membrane permeability to ceftazidime and in vivo pharmacokinetics during continuous renal replacement therapies. Antimicrobial Agents Chemotherapy, 53, 194-201.

[16] Conil, J.M., Georges, B., Lavit, M., Laguerre, J., Samii, K., Houin, G., Saivin, S., 2007, Intermittent administration of ceftazidime to burns patients: influence of glomerular filtration. Brazilian Journal of Clinical Pharmacology, 22, 125-133.

[17] Sader, H.S., Bhavnani, S.M., Ambrose, P.G., Jones, R.N., Pfaller, M.A., 2007, Re-evaluation of the role of broad-spectrum cephalosporins against staphylococci by applying contemporary in-vitro results and pharmacokinetic-pharmacodynamic principles. Journal of Chemotherapy, $19,38-43$

[18] Abdel-Khalek, M.M., Mahrous, M.S., 1984, Use of ammonium molybdate in the colorimetric assay of cephalosporins, Talanta, 31, 635-637.

[19] Navarro, P.G., and Las Parras, P.M., 1991, Reaction of sodium amoxicillin with $\mathrm{Cu}(\mathrm{II})$ ion in a methanolic medium, J. Pharm. Sci., 80, 904-907.

[20] Zuhri, A.Z.A., Rady, A.H., El-Shahawi, M.S., Al-Dhaheri, S., 1994, Spectrophotometric determination of ampicillin by ternary complex formation with 1,10-phenantroline and copper(II), Microchem. J., 50, 111-115.

[21] Ayad, M.M., Shalaby, A.A., Abdellatef, H.E., Elsaid, H.M., 1999, Spectrophotometric determination of certain cephalosporins through oxidation with cerium (IV) and 1-chlorobenzotriazole, J. Pharm. Biomed. Anal., 20, 557-564.

[22] Al-Momani, I.F., 2001, Spectrophotometric determination of selected cephalosporins in drug formulations using flow injection analysis, J. Pharm. Biomed. Anal., 25, 751-757.

[23] Mohamed, G.G., 2001, Spectrophotometric determination of ampicillin, dicluxacillin, flucoxacillin and amoxicillin antibiotic drugs: ion-pair formation with molybdenum and thiocyanate, J. Pharm. Biomed. Anal., 24, 561-567.

[24] Martinez, L.G., Falco, P.C., Cabeza, A.S., 2002, Comparison of several methods used for the determination of cephalosporins. Analysis of cephalexin in pharmaceutical samples, J. Pharm. Biomed. Anal., 29, 405-423.

[25] Salem, H., and Askal, H., 2002, Colourimetric and AAS determination of cephalosporins using Reineck's salt, J. Pharm. Biomed. Anal., 29, 347-354.

[26] El-Mammly, M.Y., 2003, Spectrophotometric determination of flucoxacillin in pharmaceutical preparations some nitrophenols as a complexing agent, Spectrochim. Acta, 59, 771-776.

[27] Amin, A.S., and Ragab, G.H., 2004, Spectrophotometric determination of certain cephalosporins in pure form and in pharmaceutical formulations, Spectrochim. Acta, 60, 2831-2835.

[28] Nascimento, J.W.L., Omosako, C.E., Carmona, M.J., Auler Junior, J.O., Santos, S.R.C.J., 2003, Micrométodo para quantificação de cefuroxima em plasma através da cromatografia líquida de alta eficiência. Aplicação na profilaxia de pacientes submetidos à cirurgia cardíaca. Br. J. Pharm. Sci., 39, 265-272.
[29] Joshi, S., 2002, HPLC separation of antibiotics present in formulated and unformulated samples, J. Pharm. Biomed. Anal., 28, 795-809.

[30] Samanidou, V.F., Hapeshi, E.A., Papadoyannis, I.N., 2003, Rapid and sensitive high-performance liquid chromatographic determination of four cephalosporins antibiotics in pharmaceuticals and body fluids, J. Chromatogr. B, 788, 147-158.

[31] Zajac, M., Jelinska, A., Dobrowolski, L., Oszczapowicz, I., 2003, Evaluation of stability of cefuroxime in solid state, J. Pharm. Biomed. Anal., 32, 1181-1187.

[32] Zivanovic, L., Ivanovic, I., Vladimirov, S., Zecevic, M., 2004, Investigation of chromatographic conditions for the separation of cefuroxime axetil and its geometric isomer, J. Chromatogr. B, 800, 175-179.

[33] Castaneda, P.G., Julien, E., Fabra, H., 1996, Cross validation of capillary electrophoresis and high-performance liquid chromatography for cefotaxime and related impurities, J. Chromatogr., 42, 159-164.

[34] Fabre, H., Blanchin, M.D., Lerner, D., Mandrou, B., 1985, Determination of cephalosporins utilizing thin-layer chromatography with fluorescence detection, Analyst, 110, 775.

[35] Korany, M.A., El-Sayed, H.M.A., Galal, S.M., 1989, The applications of a new chromogenic and fluorescent reagent for cobalt(II), Anal. Lett., 22, 619-622.

[36] Farrell, C.D., Rowell, F.J., Cumming, R.H., 1995, A rapid fluorescence ELISA for ceftazidime, Anal. Proc., 32, 205-206.

[37] Aly, F.A., Hefnawy, M.M., Belal, F., 1996, A selective spectro-fluorimetric method for the determination of cephalosporins in biological fluids, Anal. Lett., 29, 1.

[38] Yang, J.H., Zhou, G.J., Jie, N.Q., Han, R.J., Lin, C.G., Hu, J.T., 1996, Simultaneous determination of cephalexin and cephadroxil by using the coupling technique of synchronous fluorimetry and H-point standard additions method, Anal. Chim. Acta, 325, 195-200.

[39] Sengun, F.I., Ulas, K., Fedai, I., 1985, Analytical investigations of cephalosporins-II. Polarographic behaviour of ceftriaxone, cefuroxime, cefotaxime and ceftizoxime and assay of their formulations, J. Pharm. Biomed. Anal., 3, 191-199.

[40] Altinoz, S., Ozer, D., Temizer, A., Yuksel, N., 1994, Determination of ceftriaxone in aqueous humour and serum samples by differential-pulse adsorptive stripping voltametry, Analyst, 119, 1575-1577.

[41] El-Maali, N.A., Ali, A.M.M., Ghandour, M.A., 1994, Square-wave voltametric determination of cefoperazone in a bacterial culture, pharmaceutical drug, milk and urine, Electroanalysis, 52, 599-604.

[42] Reddy, G.V.S., and Reddy, S.J., 1997, Estimation of cephalosporin antibiotics by differential pulse polarography, Talanta, 44, 627-631.

[43] Ozkan, S.A., Erk, N., Uslu, B., Ylmaz, N., Biryol, I., 2000, Study on electrooxidation of cephadroxil monohydrate and its determination by differential pulse voltametry, J. Pharm. Biomed. Anal., 23, 263-273.

[44] Fogg, A.G., Abadía, M.A., Henriques, H.P., 1982, Titrimetric 
determination of the yield of sulphide formed by alkaline degradation of cephalosporins, Analyst, 107, 449.

[45] United States Pharmacopoeia. Rockville: United States Pharmacopeial Convention, 2008.

[46] British Pharmacopoeia. London, England: The Stationary Office, 2003.

[47] Farmacopéia Portuguesa. Lisboa, Portugal: Calouste Gulbenkian, 2005.

[48] Moreno, A.H., and Salgado, H.R.N., 2007, Microbiological assay for ceftazidime injection, J. AOAC Int., 90, 1379-1382.

[49] Moreno, A.H., and Salgado, H.R.N., 2008, Development of a new high-performance liquid chromatographic method for the determination of ceftazidime, J. AOAC Int., 91, 739-743.

[50] Moreno, A.H., and Salgado, H.R.N., 2008, Spectrophotometric determination of ceftazidime in pharmaceutical preparations using neocuproin as a complexing agent, Anal. Lett., 41, 2143-2152.

[51] Moreno, A.H., and Salgado, H.R.N., 2009, Rapid and selective UV spectrophotometric method for the analysis of ceftazidime, J. AOAC Int., 92, 820-824.

[52] Official Methods of Analysis, $17^{\text {th }}$ ed., Gaithersburg, MD: AOAC International, 2000.

[53] A. Korolkovas, Dicionário Terapêutico Guanabara, Rio de Janeiro, Brazil: Guanabara Koogan, 2000. 